\title{
Intravenous L-Carnitine and Acetyl-L-Carnitine in Medium-Chain Acyl-Coenzyme A Dehydrogenase Deficiency and Isovaleric Acidemia
}

\author{
J. L. K. VAN hOVE, S. G. KAHLER, D. S. Millington, D. S. ROE, D. H. CHACE, \\ S. J. R. HEALES, AND C. R. ROE
}

Department of Pediatrics, Division of Genetics and Metabolism, Duke University Medical Center, Durham, North Carolina 27710 [J.L.K.V.H., S.G.K., D.S.M., D.S.R., D.H.C., C.R.R.]; and Department of Child Health, Institute of Child Health, London WCIN IEH, United Kingdom [S.J.R.H.]

\begin{abstract}
The purpose of this study was to determine whether treatment with L-carnitine or acetyl-L-carnitine enhances the turnover of lipid or branched-chain amino acid oxidation in patients with inborn errors of metabolism. Increasing i.v. doses of $L$-carnitine and acetyl-L-carnitine were given to one patient with medium-chain acyl-CoA dehydrogenase deficiency and to another with isovaleric acidemia. Both patients were in stable condition and receiving oral L-carnitine supplements. The excretion of carnitine and disease-specific metabolites was measured. The incorporation of $\mathrm{L}$-carnitine in the intracellular pool was demonstrated using stable isotopes and mass spectrometry. Increasing doses of either i.v. L-carnitine or acetyl-L-carnitine did not stimulate the excretion of octanoylcarnitine in the patient with medium-chain acyl-CoA dehydrogenase deficiency, nor did it raise the plasma levels of either cis4-decenoate or octanoylcarnitine. Similarly, increasing doses of either i.v. L-carnitine or acetyl-L-carnitine did not enhance the excretion of isovalerylcarnitine in a patient with isovaleric acidemia. The excretion of isovalerylglycine actually decreased. We conclude that there was no evidence of enhanced fatty acid $\beta$-oxidation or enhanced branchedchain amino acid oxidation in vivo by the administration of high doses of $\mathrm{L}$-carnitine or acetyl-L-carnitine in these two patients. Because only one individual with each disorder was studied, the data are only indicative and may not necessarily be representative of all individuals with these disorders. Definite settlement of this issue will require further studies in additional subjects. (Pediatr Res 35: 96101, 1994)
\end{abstract}

\section{Abbreviations}

MCAD, medium-chain acyl-CoA dehydrogenase IVA, isovaleric acidemia GC/MS, gas chromatography/mass spectrometry

Treatment of the organic acidurias is based primarily on restricting dietary precursors and providing conjugating agents to remove toxic intermediates when applicable. The aim of

Received June 10, 1993; accepted August 17, 1993

Correspondence: Johan Van Hove, Division of Genetics and Metabolism, Box 3028, Duke University Medical Center, Durham, NC 27710.

Supported by FDA Orphaned Products Division Grant No. FD-R-000177 (Food and Drug Administration, Washington, DC), National Institutes of Health Grant HD-24908 (Bethesda, MD), General Clinical Research Center Grant M01-RR-30 (Division of Research Resources, NIH, Bethesda, MD), and the H. L. Holtkamp Memorial Fund (Duke Medical Center). carnitine supplementation is to correct an existing deficiency (1), restore the mitochondrial acyl-CoA/free $\mathrm{CoA}$ ratio, and provide an efficient conjugate for the excretion of accumulating toxic intermediates (2).

MCAD deficiency is the most common inherited disorder of fatty acid metabolism. Plasma and tissue free carnitine concentrations are reduced in this disorder (3), and there is increased excretion of the medium-chain acylcarnitines (4). Oral L-carnitine supplementation can normalize the plasma carnitine level and increases the excretion of octanoylcarnitine in comparison with the excretion before treatment (4-6). This enhanced excretion is further increased during acute episodes of illness (7).

The safety of L-carnitine supplementation in patients with MCAD deficiency has been questioned. In carnitine-deficient tissues, carnitine may be rate limiting and addition of $\mathrm{L}$-carnitine could enhance fatty acid oxidation (8). It has been suggested that in MCAD deficiency, L-carnitine might increase mitochondrial uptake of fatty acids and thus stimulate $\beta$-oxidation, leading to increased production of toxic intermediates (9-11).

IVA is caused by a defect in the metabolism of the amino acid leucine due to a deficiency in isovaleryl-CoA dehydrogenase. Oral L-carnitine therapy in IVA has resulted in the enhanced excretion of isovalerylcarnitine $(12,13)$. In vitro studies have indicated that $\mathrm{L}$-carnitine can enhance oxidation of the branchedchain amino acids leucine and valine in muscle homogenates (14). Theoretically, L-carnitine therapy in a patient with IVA could increase the production of isovaleryl-CoA through increased branched-chain amino acid oxidation.

This study was designed to assess the safety of L-carnitine and acetyl-L-carnitine administration to patients with metabolic disorders. Disease-specific metabolites were monitored while increasing i.v. doses of $\mathrm{L}$-carnitine were given to one patient with MCAD deficiency and to another patient with IVA. Acetyl-Lcarnitine was also investigated because it can provide the potential benefit of additional acetyl-CoA groups to the mitochondria (15).

\section{MATERIALS AND METHODS}

Subjects. Patient 1 is a $2 \frac{1}{2} 2$-y-old girl with MCAD deficiency. She was diagnosed after an episode of hypoglycemic coma at the age of 6 mo by urine organic acids, acylcarnitine profile, and fibroblast enzyme assay. She is a compound heterozygote for the common K329E mutation and a I375T mutation (16). She has been treated with restriction of fat intake to $24 \%$ of caloric intake, avoidance of fasting, and supplementation with oral Lcarnitine $620 \mu \mathrm{mol} / \mathrm{kg} / \mathrm{d}(100 \mathrm{mg} / \mathrm{kg} / \mathrm{d})$ with doubling during times of illness. She has been hospitalized on one occasion for intercurrent illness but has not had recurrence of severe symptoms while receiving therapy. At the time of the study, she was 
in good health. She had a constant intake of $88 \mathrm{kcal} / \mathrm{kg} / \mathrm{d}$ with protein $15 \%$ of calories, fat $24 \%$, and carbohydrate $61 \%$.

Patient 2 is a $51 / 2$-y-old girl with IVA. She was diagnosed at the age of 4 y 8 mo after three attacks of pancreatitis, when typical metabolites of IVA were found in her blood and urine (17). She has been treated with protein restriction $(1 \mathrm{~g} / \mathrm{kg} / \mathrm{d}$ whole protein supplemented with Maxamaid Xleu, Ross Laboratories, Columbus, $\mathrm{OH})$ and oral L-carnitine $(620 \mu \mathrm{mol} / \mathrm{kg} / \mathrm{d}=100 \mathrm{mg} / \mathrm{kg} / \mathrm{d})$. She has been healthy since initiation of the therapy. She did not receive supplemental glycine. During the study, she had a constant intake of $75 \mathrm{kcal} / \mathrm{kg} / \mathrm{d}$ with protein $20 \%$ of caloric intake, fat $16 \%$, and carbohydrate $79 \%$. Leucine intake was $33 \mathrm{mg} / \mathrm{kg}$ / d.

Study Protocols. Intravenous L-carnitine study. On admission, patients were receiving $620 \mu \mathrm{mol} / \mathrm{kg} / \mathrm{d}(100 \mathrm{mg} / \mathrm{kg} / \mathrm{d})$ oral Lcarnitine divided in four doses. The next day, $93 \mu \mathrm{mol} / \mathrm{kg} / \mathrm{d}(15$ $\mathrm{mg} / \mathrm{kg} / \mathrm{d}$ ) i.v. L-carnitine was given divided in four doses to provide the same amount of L-carnitine based on the assumption of $15 \%$ bioavailability of the oral dose $(18,19)$. On each of the following $2 \mathrm{~d}$, the dose of i.v. L-carnitine was doubled to a maximal intake of $372 \mu \mathrm{mol} / \mathrm{kg} / \mathrm{d}(60 \mathrm{mg} / \mathrm{kg} / \mathrm{d})$ divided in four doses.

Intravenous acetyl-L-carnitine study. Initially, the patients received oral acetyl-L-carnitine $620 \mu \mathrm{mol} / \mathrm{kg} / \mathrm{d}(126 \mathrm{mg} / \mathrm{kg} / \mathrm{d})$ divided in four doses for $2 \mathrm{~d}$. Then $93 \mu \mathrm{mol} / \mathrm{kg} / \mathrm{d}(18.9 \mathrm{mg} / \mathrm{kg} /$ d) acetyl-L-carnitine was given i.v. divided in four doses to provide an equivalent dose assuming an absorption of $15 \%$ of the oral dose (by analogy to L-carnitine; no data available). Subsequently, this dose was doubled twice over $2 \mathrm{~d}$ to a maximum intake of i.v. acetyl-l-carnitine $372 \mu \mathrm{mol} / \mathrm{kg} / \mathrm{d}(75.6 \mathrm{mg} /$ $\mathrm{kg} / \mathrm{d}$ ) divided in four doses.

Isotope labeling studies. To study the metabolic fate of the administered L-carnitine and acetyl-L-carnitine, two separate stable isotope-labeled studies were done. These studies involved single bolus i.v. doses of $\left[{ }^{2} \mathrm{H}_{3}\right.$-methyl] $\mathrm{L}$-carnitine $93 \mu \mathrm{mol} / \mathrm{kg}$ $(15.3 \mathrm{mg} / \mathrm{kg})$ and acetyl- $\left[{ }^{2} \mathrm{H}_{3}\right.$-methyl $] \mathrm{L}$-carnitine $93 \mu \mathrm{mol} / \mathrm{kg}$ $(19.3 \mathrm{mg} / \mathrm{kg})$. These experiments were done on different days with urine collected for $24 \mathrm{~h}$ in each case.

Before these studies were done, both patients had been on oral L-carnitine supplementation $(100 \mathrm{mg} / \mathrm{kg} / \mathrm{d})$. A washout period of $1 \mathrm{~d}$ on baseline oral L-carnitine therapy was scheduled between studies of L-carnitine and acetyl-L-carnitine administration. Intravenous doses were given as a slow push over 3 to $5 \mathrm{~min}$. Daily timed 24-h urine collections were obtained for the measurement of free L-carnitine, acetyl-L-carnitine, and the appropriate acylcarnitine species (octanoylcarnitine in patient 1 and isovalerylcarnitine in patient 2 ). Isovalerylglycine and benzoylglycine were measured in the urine collections of patient 2 . Blood samples were obtained for cis-4-decenoate and octanoylcarnitine levels in patient 1 .

Daily oral intake was monitored to assure a steady intake of relevant nutrients. Blood samples were analyzed for routine hematologic studies, electrolytes, transaminases, calcium, phosphorus, and alkaline phosphatases, ammonia, and lactate.

L-Carnitine and acetyl-L-carnitine were a gift from Sigma Tau Pharmaceuticals (Rome, Italy). Octanoyl-DL-carnitine was purchased from Sigma Chemical Co. (St. Louis, MO). The labeled compounds $\left[{ }^{2} \mathrm{H}_{3}\right.$-methyl $] \mathrm{L}$-carnitine, acetyl- $\left[{ }^{2} \mathrm{H}_{3}\right.$-methyl $]$ L-carnitine and octanoyl- $\left[{ }^{2} \mathrm{H}_{3}\right.$-methyl $] \mathrm{L}$-carnitine were synthesized according to methods previously described $(20,21)$. Isovalerylglycine was a gift of Dr. R. Chalmers (St. George's Medical Center, London, UK) and $\left[{ }^{2} \mathrm{H}_{3}\right.$-methyl]isovalerylglycine was a gift of Dr. P. Rinaldo (Yale University, New Haven, CT). N-benzoyl$\left[2,2{ }^{2} \mathrm{H}_{2}\right]$ glycine (98.7 atom \% pure) was purchased from MSD Isotopes, Merck \& Co. (Rahway, NJ). Chemical and isotopic purity of these standards was confirmed by mass spectrometry and nuclear magnetic resonance spectrometry. $\mathrm{N}$-methyl-N-trimethylsilyl-trifluoroacetamide was purchased from Pierce (Rockford, IL).

Twenty-four-h urine collections were analyzed for free L- carnitine (22), acetyl-L-carnitine, and appropriate acylcarnitines (either octanoylcarnitine or isovalerylcarnitine) by fast atom bombardment tandem mass spectrometry with isotope-labeled internal standards using previously published methods (23). Plasma carnitine levels were measured by radioenzymatic assay (24). Plasma octanoylcarnitine was measured by fast atom bombardment tandem mass spectrometry as previously described (25). Standard addition of octanoyl-D,L-carnitine to control plasma samples over a concentration range of 0.2 to $8 \mathrm{nmol} / \mathrm{mL}$ $(r=0.99, n=9)$ produced a linear calibration and the coefficient of variation for the overall assay was $4.4 \%(n=7)$. Cis-4decenoate was measured by GC/MS in extracts of $50 \mu \mathrm{L}$ of plasma spotted on filter paper as previously described $(26,27)$. Isovalerylglycine was quantified by GC/MS using selected ion monitoring, as follows: $100 \mu \mathrm{L}$ of urine plus $50 \mu \mathrm{g}$ of $\left[{ }^{2} \mathrm{H}_{3}\right.$-methyl]isovalerylglycine was diluted to $1 \mathrm{~mL}$ and extracted three times with ethyl acetate after acidification with $\mathrm{HCl}$ and saturation with $\mathrm{NaCl}$. After drying under a gentle stream of nitrogen, the sample was derivatized with $75 \mu \mathrm{L}$ of $\mathrm{N}$-methyl-Ntrimethylsilyl-trifluoroacetamide at $80^{\circ} \mathrm{C}$ for $3 \mathrm{~h}$. Isovalerylglycine-(bis)-TMS was monitored as the molecular ion at $\mathrm{m} / \mathrm{z} 303.3$ and $\left[{ }^{2} \mathrm{H}_{3}\right.$-methyl]isovalerylglycine-(bis)-TMS at $\mathrm{m} / \mathrm{z} 306.3$ on a VG-TRIO-1 mass spectrometer (Fisons Instruments, Danvers, MA) after capillary column gas chromatography (DB-1; $30 \mathrm{~m} \times$ $0.25 \mathrm{~mm} ; 1-\mu \mathrm{m}$ film thickness, from $\mathrm{J} \& \mathrm{~W}$ Scientific, Folsom, CA). The following conditions were used: helium flow rate 1 $\mathrm{mL} / \mathrm{min}$, injector temperature $250^{\circ} \mathrm{C}$, injector split ratio $20: 1$, oven temperature $120^{\circ} \mathrm{C}$ for $5 \mathrm{~min}$, then increased at $5^{\circ} \mathrm{C} / \mathrm{min}$ to $300^{\circ} \mathrm{C}$. Isovalerylglycine eluted at $16.55 \mathrm{~min}$ and $\left[{ }^{2} \mathrm{H}_{3}\right.$-methyl] isovalerylglycine eluted at $16.52 \mathrm{~min}$. Linear calibration of the assay was verified by addition of known amounts of isovalerylglycine to control urine over a range of 63-18 $900 \mu \mathrm{mol} / \mathrm{L}(10$ $3000 \mu \mathrm{g} / \mathrm{mL})(r=0.98)$. N-benzoyl-glycine (hippurate) was measured by a variation of a previously published tandem mass spectrometric assay (28). To $20 \mu \mathrm{L}$ of urine were added 100 nmol N-benzoyl-[2,2 $\left.{ }^{2} \mathrm{H}_{2}\right]$ glycine (internal standard). After evaporating the solvent under nitrogen, the residue was derivatized with $100 \mu \mathrm{L}$ of $\mathrm{n}$-butanol in $3 \mathrm{M} \mathrm{HCl}$ at $65^{\circ} \mathrm{C}$ for $15 \mathrm{~min}$. After evaporation of excess reagent, the residue was dissolved in $50 \mu \mathrm{L}$ of a matrix of 1:1 methanol:glycerol. The precursor ions of the benzoyl fragment ion $(\mathrm{m} / \mathrm{z} 105)$ were monitored. The intensity ratio of the precursor ions, corresponding to the molecular ion masses of benzoylglycine and the internal standard $(\mathrm{m} / \mathrm{z}$ 236:238), was determined. The assay was linear for the addition of known amounts of benzoylglycine over a concentration range of 0.47 to $47 \mathrm{mM}\left(r^{2}=0.999\right)$. The coefficient of variation was $4.2 \%(n=10)$ at a concentration of $11.5 \mathrm{mM}$

Hematologic studies and analysis of electrolytes, liver function tests, ammonia, and lactate were performed by the Duke Hospital Laboratories by standard procedures.

Ethics. The study was approved by the Duke Institutional Review Board (IRB 124-93-IR 10). The patients were admitted to the clinical research unit and informed consent was obtained from a parent.

\section{RESULTS}

Baseline plasma carnitine and acylcarnitine levels in the patient with MCAD deficiency (patient 1) were $42 \mu \mathrm{M}$ (free carnitine), $8 \mu \mathrm{M}$ (short-chain acylcarnitine), and $4 \mu \mathrm{M}$ (long-chain acylcarnitine). In patient 2 , with IVA, the corresponding levels were $88 \mu \mathrm{M}, 33 \mu \mathrm{M}$, and $4 \mu \mathrm{M}$. In patient 1 , increasing doses of i.v. L-carnitine above the equivalent oral maintenance level had no perceptible effect on the excretion of octanoylcarnitine or acetylcarnitine but increased the excretion of free carnitine by about $50 \%$ of the administered dose (Fig. $1 A$ ). Administration of i.v. acetyl-L-carnitine in increasing doses had no measurable effect on the octanoylcarnitine excretion in this patient (Fig. $1 B$ ), but the excretion of acetylcarnitine and free carnitine increased. 

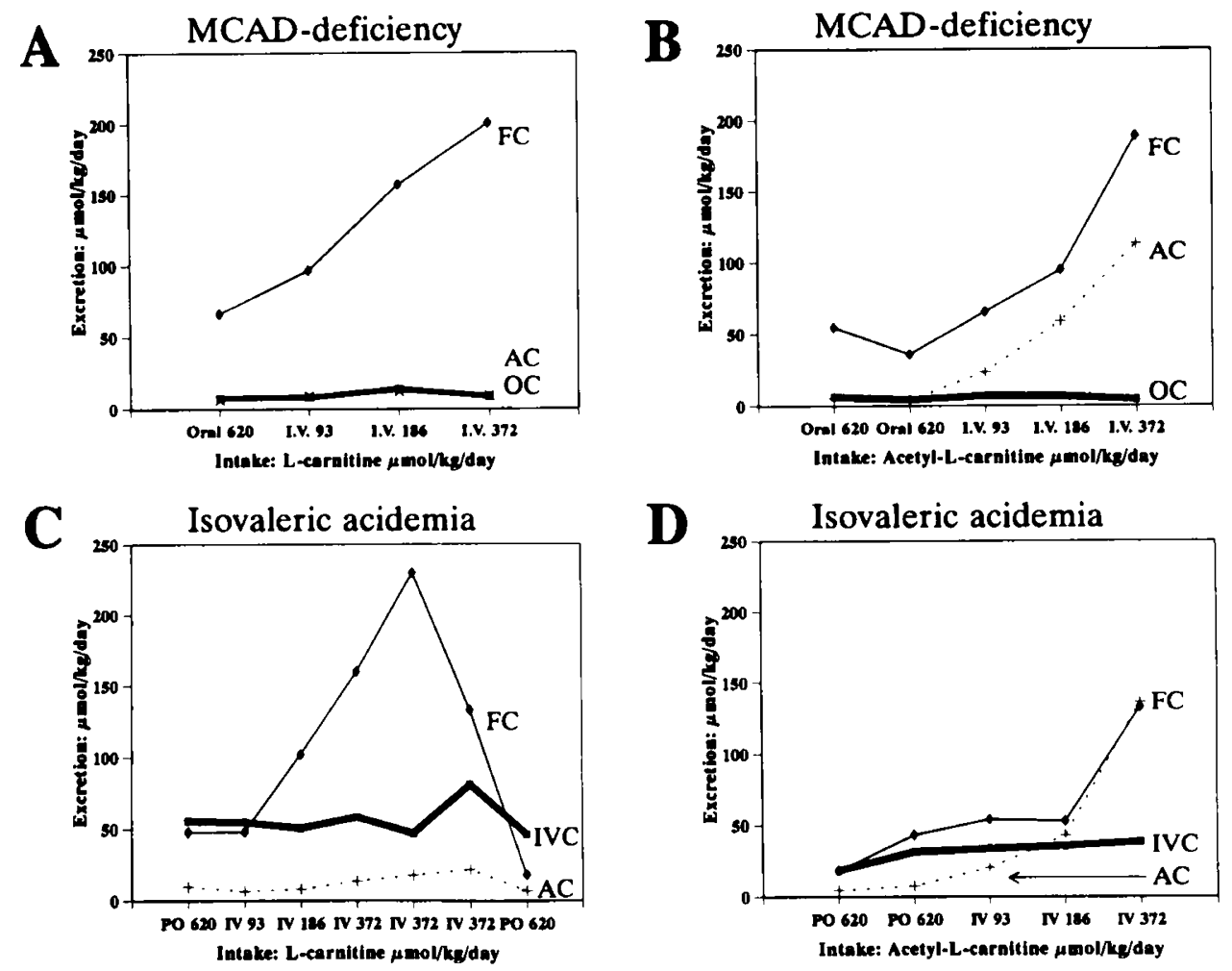

Fig. 1. After $1 \mathrm{~d}$ of oral L-carnitine $(A)$ or acetyl-L-carnitine $(B)$, increasing doses of i.v. L-carnitine were given and the daily urinary excretion of free carnitine $(F C$, thin line), octanoylcarnitine $(O C$, thick line), and acetylcarnitine $(A C$, broken line) (same levels as octanoylcarnitine) was measured in the same patient with MCAD deficiency. After $1 \mathrm{~d}$ of oral L-carnitine $(C)$ or acetyl-L-carnitine $(D)$, increasing doses of i.v. L-carnitine $(C)$ or acetyl-L-carnitine $(D)$ were given to the same patient with IVA and the daily urinary excretion of free carnitine $(F C$, thin line), acetylcarnitine $(A C$, broken line), and isovalerylcarnitine (IVC, thick line) was measured.

The plasma concentrations of cis-4-decenoate and octanoylcarnitine showed no relationship to the administered doses of either L-carnitine or acetyl-L-carnitine (Table 1).

In the patient with IVA, increasing i.v. doses above maintenance level of either L-carnitine (Fig. $1 C$ ) or acetyl-L-carnitine (Fig. 1D) did not stimulate the excretion of isovalerylcarnitine. Isovalerylglycine excretion actually fell during high-dose therapy (Table 2). During administration of high doses of L-carnitine, the molar excretion of isovalerylglycine approached the excretion of isovalerylcarnitine (Fig. $1 C$, Table 2 ) in this patient, who was not supplemented with glycine; however, at the commonly used oral maintenance dose, the isovalerylglycine concentration was considerably higher than that of isovalerylcarnitine. Benzoylglycine excretion was essentially unaffected by increasing doses of both L-carnitine and acetyl-L-carnitine.

Incorporation studies were performed by sequential i.v. infu-

Table 1. Plasma $C_{8}$-acylcarnitine and cis-4-decenoate in MCAD patient*

\begin{tabular}{lcll}
\hline \multicolumn{1}{c}{ Given } & $\begin{array}{c}\text { Dose } \\
(\mu \mathrm{mol} / \mathrm{kg} / \mathrm{d})\end{array}$ & $\begin{array}{c}\mathrm{C}_{8} \text {-acylcarnitine } \\
(\mu \mathrm{M})\end{array}$ & $\begin{array}{c}\text { cis-4-decenoate } \\
(\mu \mathrm{M})\end{array}$ \\
\hline p.o. Carnitine $\dagger$ & 620 & $1.56,5.66$ & $9.4,37.0$ \\
i.v. Carnitine & 93 & 2.79 & 24.2 \\
i.v. Carnitine & 186 & Not available & Not available \\
i.v. Carnitine & 372 & 3.49 & 7.4 \\
p.o. Acetyl-L-carnitine & 620 & 4.39 & 23.7 \\
i.v. Acetyl-L-carnitine & 93 & 1.47 & 22.2 \\
i.v. Acetyl-L-carnitine & 186 & 0.98 & 3.8 \\
i.v. Acetyl-L-carnitine & 372 & Not available & Not available \\
\hline
\end{tabular}

* The plasma concentrations of $\mathrm{C}_{8}$-acylcarnitine and cis-4-decenoate were monitored while increasing doses of i.v. L-carnitine or acetyl-Lcarnitine were given to the patient with MCAD deficiency.

+ Results from 2 different days.
Table 2. Excretion of acylglycines in patient with isovaleric acidemia*

\begin{tabular}{lcll}
\hline \multicolumn{1}{c}{ Given } & $\begin{array}{c}\text { Dose } \\
(\mu \mathrm{mol} / \mathrm{kg} / \mathrm{d})\end{array}$ & $\begin{array}{c}\text { Isovalerylglycine } \\
(\mu \mathrm{mol} / \mathrm{kg} / \mathrm{d})\end{array}$ & $\begin{array}{c}\text { Hippurate } \\
(\mu \mathrm{mol} / \mathrm{kg} / \mathrm{d})\end{array}$ \\
\hline p.o. Carnitine $\dagger$ & 620 & 160,198 & 24,82 \\
i.v. Carnitine & 93 & 189 & 555 \\
i.v. Carnitine & 186 & 158 & 228 \\
i.v. Carnitine $\dagger$ & 372 & $84,87,59$ & $689,316,208$ \\
p.o. Acetyl-L-carnitine & 620 & 134,147 & 25,20 \\
i.v. Acetyl-L-carnitine & 93 & 136 & 70 \\
i.v. Acetyl-L-carnitine & 186 & 19 & 38 \\
i.v. Acetyl-L-carnitine & 372 & 85 & 77 \\
\hline
\end{tabular}

* The excretion of isovalerylglycine and benzoylglycine (hippurate) were monitored after the administration of increasing doses of i.v. Lcarnitine or acetyl-L-carnitine to the patient with IVA.

+ Results from 2 different days.

$\ddagger$ Results from 3 different days.

sion of stable isotope-labeled L-carnitine and acetyl-L-carnitine. For the patient with MCAD deficiency, the acylcarnitine profiles for the 24-h urine collections before and after the isotope infusion are shown in Figure $2 A$ and $B$. The incorporation of isotopically labeled carnitine into the acylcarnitines is clearly demonstrated by the appearance of new molecular ion signals with a shift of +3 mass units, corresponding to acetyl- ${ }^{2} \mathrm{H}_{3}$-carnitine $(\mathrm{m} / \mathrm{z} 221)$, hexanoyl- ${ }^{2} \mathrm{H}_{3}$-carnitine $(\mathrm{m} / \mathrm{z} 277)$, octenoyl- ${ }^{2} \mathrm{H}_{3}$-carnitine $(\mathrm{m} / \mathrm{z}$ $303)$, octanoyl- ${ }^{2} \mathrm{H}_{3}$-carnitine $(\mathrm{m} / \mathrm{z} 305)$, and decenoyl- ${ }^{2} \mathrm{H}_{3}$-carnitine $(\mathrm{m} / \mathrm{z} 331)$ (Fig. 2B). The signals for free carnitine and ${ }^{2} \mathrm{H}_{3^{-}}$ carnitine appear at $\mathrm{m} / \mathrm{z} 176$ and 179 , respectively. An i.v. bolus of acetyl- $\left[{ }^{2} \mathrm{H}_{3}\right.$-methyl] $\mathrm{L}$-carnitine given to this patient resulted in the excretion of the same isotopically labeled metabolites (Fig. 2C).

When the patient with IVA was given an i.v. bolus of 

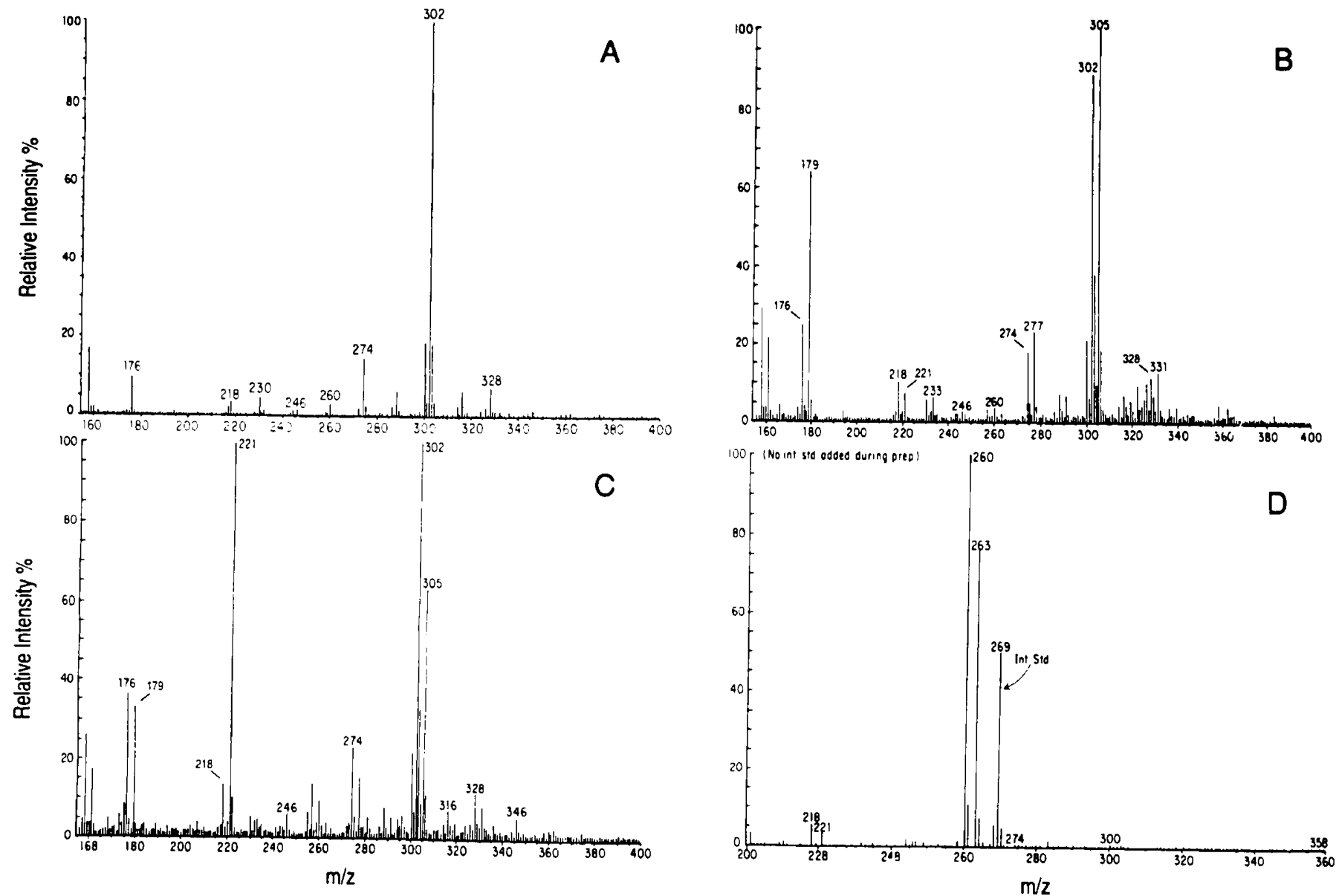

Fig. 2. $A$, The 24-h urine collection of patient 1 with MCAD deficiency on i.v. L-carnitine shows the excretion of the carnitine esters $\mathrm{C}_{8 \cdot 0}$ (octanoylcarnitine) $(\mathrm{m} / \mathrm{z} 302), C_{6: 0}$ (hexanoylcarnitine) $(\mathrm{m} / \mathrm{z} 274)$, and $C_{10: 0}$ (decenoylcarnitine) $(\mathrm{m} / \mathrm{z} 328)$, and free carnitine $(\mathrm{m} / \mathrm{z} 176)$. In the same patient, after a single bolus of $\left[{ }^{2} \mathrm{H}_{3}\right.$-methyl $] \mathrm{L}$-carnitine $(B)$, patient urine shows excretion of octanoyl- ${ }^{2} \mathrm{H}_{3}$-carnitine $(\mathrm{C} 8: 0, \mathrm{~m} / \mathrm{z} 305)$, hexanoyl- ${ }^{2} \mathrm{H}_{3}-$ carnitine (C6:0, m/z 277), octenoyl- ${ }^{2} \mathrm{H}_{3}$-carnitine $(\mathrm{C} 8: 1, \mathrm{~m} / \mathrm{z} 303)$, and decenoyl- ${ }^{2} \mathrm{H}_{3}$-carnitine $(\mathrm{C} 10: 1, \mathrm{~m} / \mathrm{z} 331)$ by a +3 shift in the mass spectra of the corresponding acylcarnitines. A similar profile is obtained after the administration of a single bolus of acetyl- $\left[{ }^{2} \mathrm{H}_{3}-\right.$ methyl $_{\mathrm{L}} \mathrm{L}-\mathrm{carnitine}(C) . D, \mathrm{In}$ the patient with IVA, after a single bolus of $\left[{ }^{2} \mathrm{H}_{3}\right.$-methyl $] \mathrm{L}$-carnitine, the excretion of isovaleryl- ${ }^{2} \mathrm{H}_{3}$-carnitine $(\mathrm{m} / \mathrm{z} 263)$ became prominent with a shift of +3 to the excretion of the normal isovalerylcarnitine $(\mathrm{m} / \mathrm{z} 260)$ in the acylcarnitine profile.

$\left[{ }^{2} \mathrm{H}_{3}\right.$-methyl $]$ carnitine, a new signal in the urine acylcarnitine profile was observed at $\mathrm{m} / \mathrm{z} 263$, corresponding to isovaleryl${ }^{2} \mathrm{H}_{3}$-carnitine, in addition to that of the unlabeled isovalerylcarnitine (m/z 260) (Fig. 2D).

Both patients remained in stable condition throughout the admission, and hematologic parameters and blood chemistry remained unchanged.

\section{DISCUSSION}

This limited study was designed to evaluate the metabolic effect of increasing dosage of $L$-carnitine and acetyl-L-carnitine in patients with inborn errors of metabolism. We carefully studied two patients in a stable metabolic state, one with MCAD deficiency and one with IVA. In the patient with MCAD deficiency, increasing doses of either L-carnitine or acetyl-L-carnitine did not stimulate the excretion of octanoylcarnitine or increase plasma cis-4-decenoate or plasma octanoylcarnitine. Similarly, in the patient with IVA, increasing doses of L-carnitine or acetyl$\mathrm{L}$-carnitine did not result in enhanced excretion of isovalerylcarnitine. The excretion of isovalerylglycine actually decreased, and the excretion of benzoylglycine was unaffected.

Intravenous administration of L-carnitine and acetyl-L-carnitine specifically labeled with three deuterium atoms in one of the N-methyl groups resulted in the incorporation of the label into all the acylcarnitines excreted. There was no obvious preference for particular acyl groups as shown by similar enrichment into the different species (Fig. 2). This provides direct evidence that carnitine administered enters the mitochondrial pool and rapidly forms acylcarnitines with all available acyl groups, including both the disease-specific and normal species. Acetylcarnitine also exchanges with the acylcarnitine pool.

Previous pharmacokinetic studies have shown that increasing doses of oral L-carnitine do not result in increasingly higher plasma levels, whereas higher plasma levels and higher areas under the curve are achieved by i.v. administration of L-carnitine (19). This might be explained by the partially carrier-mediated, saturable intestinal uptake of carnitine (29-31), with incomplete absorption at pharmacologic doses (32). Furthermore, orally administered acetyl-L-carnitine did not result in the increased excretion of acetylcarnitine, as observed after i.v. administration (Fig. $1 B$ and $D$ ). We ascribe this to the substantial deacetylation of acetyl-L-carnitine in the intestinal mucosa, also reported in animal studies (33). Other workers have observed the same phenomenon (34). Intravenous acetyl-L-carnitine produced high plasma acetylcarnitine levels (35). For these reasons, we investigated the increased intake of carnitine and acetylcarnitine by the i.v. route.

In this study, similar excretion of L-carnitine and acylcarnitines was achieved after switching to i.v. administration at $15 \%$ of the previously administered oral dose (Fig. 1). These data are in 
agreement with the previously reported estimate of about $15 \%$ bioavailability of orally administered carnitine in healthy subjects $(18,19)$. The starting point for i.v. dosage was therefore equivalent to the maintenance oral dose.

From the isotope labeling studies, it is clear that L-carnitine and acetylcarnitine administered i.v. enter the mitochondria and equilibrate with the endogenous pool. In the patient with MCAD deficiency, doubling and even quadrupling the i.v. dosage did not affect either the plasma concentrations of octanoylcarnitine and cis-4-decenoic acid, or the excretion of octanoylcarnitine. This implies that increased intake of L-carnitine does not of itself stimulate the $\beta$-oxidation of fatty acids in vivo. This is in keeping with the biochemical observation that the rate of fatty acid oxidation is primarily dependent on the concentration of malonyl-CoA rather than the concentration of carnitine $(36,37)$.

In the patient with IVA, the fact that isovalerylcarnitine excretion was stable while the excretion of isovalerylglycine, the major metabolite in this disorder (38), decreased by about $50 \%$ on the highest dose of i.v. L-carnitine implies that increased intake of carnitine does not stimulate the production of isovaleryl-CoA. On the contrary, the accumulation of this toxic intermediate apparently decreases. Inhibition of the glycine- $\mathrm{N}$-acylase by carnitine therapy (39) is an unlikely explanation for this observation, because the excretion of benzoylglycine, whose formation depends on the same enzyme, is unaffected. Furthermore, no concomitant increase was observed in the excretion of 3-hydroxyisovaleric acid, which is also derived from isovaleryl-CoA, according to GC/MS analysis. Because diagnostic metabolites in IVA are primarily derived from endogenous protein turnover (40), we conclude that increasing dosage of i.v. L-carnitine does not enhance branched-chain amino acid catabolism in humans, similar to previously reported observations in normal humans and rats $(41-43)$. Rather, it is possible that higher levels of isovalerylcarnitine in the liver might reduce protein degradation $(44,45)$. This is one potential explanation for the observation that patients with IVA can be equally cared for with either L-carnitine therapy or with glycine therapy $(12,13,46,47)$, despite the fact that the excretion of isovalerylcarnitine is less than the excretion of isovalerylglycine.

Enhanced excretion of abnormal acylcarnitines upon supplementation with carnitine in MCAD deficiency and in IVA is well documented $(4,12)$. This study indicates that for patients with MCAD deficiency and/or IVA in a stable state, a dose of $620 \mu \mathrm{mol} / \mathrm{kg} / \mathrm{d}(100 \mathrm{mg} / \mathrm{kg} / \mathrm{d})$ oral L-carnitine should provide adequate carnitine availability both to normalize the plasma free carnitine concentration and to provide optimal excretion of the major accumulating abnormal acylcarnitine species. These preliminary data suggest that carnitine administration enhances excretion of accumulated metabolites without further stimulation of their formation. During metabolic crises, patients with MCAD deficiency and IVA rapidly accumulate toxic acyl-CoA intermediates, increasing the need for detoxifying agents. The increased excretion of the disease-specific acylcarnitines during such episodes (7) illustrates this. This limited study supports the safety of i.v. L-carnitine administration. Because only one individual with each disorder was studied while metabolically stable, the data are only indicative and may not necessarily be representative of all individuals with these disorders. Definite settlement of this issue will require further studies in additional subjects.

Acknowledgments. The authors thank Sigma Tau Pharmaceuticals (Pomezia, Rome, Italy) for a generous supply of L-carnitine and VG MassLab (Manchester, UK) for the temporary loan of a TRIO-3 tandem quadrupole mass spectrometer.

\section{REFERENCES}

1. Chalmers RA, Roe CR, Stacey TE, Hoppel CL 1984 Urinary excretion of Lcarnitine and acylcarnitines by patients with disorders of organic acid me- tabolism: evidence for secondary insufficiency of L-carnitine. Pediatr Res 18:1325-1328

2. Chalmers RA, Roe CR, Tracey BM, Stacey TE, Hoppel L, Millington DS 1983 Secondary carnitine insufficiency in disorders of organic acid metabolism: modulation of acyl-CoA/CoA ratios by L-carnitine in vivo. Biochem Soc Trans 11:724-725

3. Stanley CA, Hale DE, Coates PM, Hall CL, Corkey BE, Yang W, Kelley RI, Gonzales EL, Williamson JR, Baker L 1983 Medium-chain acyl-CoA dehydrogenase deficiency in children with non-ketotic hypoglycemia and low carnitine levels. Pediatr Res 17:877-883

4. Roe CR, Millington DS, Maltby DA, Bohan TP, Kahler SG, Chalmers RA 1985 Diagnostic and therapeutic implications of medium-chain acylcarnitines in the medium-chain acyl-CoA dehydrogenase deficiency. Pediatr Res 19:459-466

5. Roe CR, Coates PM 1989 Acyl-CoA dehydrogenase deficiencies In: Scriver CR, Beaudet AL, Sly WS, Valle D (eds) The Metabolic Basis of Inherited Disease, 6th ed. McGraw-Hill, New York, vol 1, pp 889-914

6. Schmidt-Sommerfeld E, Penn D, Kerner J, Bieber LL, Rossi TM, Lebenthal E 1989 Quantification of urinary carnitine esters in a patient with mediumchain acyl-coenzyme $A$ dehydrogenase deficiency: effect of metabolic state and L-carnitine therapy. J Pediatr 115:577-582

7. Roe CR, Millington DS, Kahler SG, Kodo N, Norwood DL 1990 Carnitine homeostasis in the organic acidurias. In: Tanaka K, Coates P (eds) Fatty Acid Oxidation: Clinical, Biochemical, and Molecular Aspects. Alan R. Liss Inc., New York, pp 383-402

8. Long CS, Haller RG, Foster DW, McGarry JD 1982 Kinetics of carnitinedependent fatty acid oxidation: implications for human carnitine deficiency. Neurology 32:663-666

9. Treem WR, Stanley CA, Goodman SI 1989 Medium-chain acyl-CoA dehydrogenase deficiency: metabolic effects and therapeutic efficacy of long-term Lcarnitine supplementation. J Inherit Metab Dis 12:112-119

10. Stanley CA 1990 Disorders of fatty acid oxidation. In: Fernandes J, Saudubray J-M, Tada K (eds) Inborn Metabolic Diseases. Diagnosis and Treatment. Springer-Verlag, Berlin, pp 395-410

11. Chalmers RA 1987 Disorders of organic acid metabolism In: Holton JB (ed) The Inherited Metabolic Diseases. Churchill-Livingstone, Edinburgh, pp 141-214

12. Roe CR, Millington DS, Maltby DA, Kahler SG, Bohan TP 1984 L-Carnitine therapy in isovaleric acidemia. J Clin Invest 74:2290-2295

13. de Sousa C, Chalmers RA, Stacey TE, Tracey BM, Weaver CM, Bradley D 1986 The response to $L$-carnitine and glycine therapy in isovaleric acidaemia. Eur J Pediatr 144:451-456

14. van Hinsberg VW, Veerkamp JH, Engelen PJM, Ghijsen WJ 1978 Effect of Lcarnitine on the oxidation of leucine and valine by rat skeletal muscle. Biochem Med Metab Biol 20:115-124

15. Bartlett K, Bhuiyan AKMJ, Aynsley-Green A, Butler PC, Alberti KGMM 1989 Human forearm arteriovenous differences of carnitine, short-chain acylcarnitine and long-chain acylcarnitine. Clin Sci 77:413-416

16. Ding JH, Bross $P$, Yang BZ, lafolla AK, Millington DS, Roe CR, Gregersen N, Chen YT 1992 Genetic heterogeneity in MCAD deficiency: frequency of $\mathrm{K} 329 \mathrm{E}$ allele and identification of three additional mutant alleles. In: Coates PM, Tanaka K (eds) New Developments in Fatty Acid Oxidation. WileyLiss, New York, pp 479-488

17. Kahler SG, Woolf DA, Leonard JV, Zaritsky A, Lawless ST, Sherwood WG 1990 Pancreatitis and organic acidurias: an under-recognized association? Vth International Congress on Inborn Errors of Metabolism, W5:4. Asilomar, CA(abstr)

18. Segre G, Bianchi E, Corsi M, D'Iddio S, Ghirardi O, Maccari F 1988 Plasma and urine pharmacokinetics of free and of short-chain carnitine after administration of carnitine in man. Arzneimittelforschung 38:1830-1834

19. Harper $P$, Elwin CE, Cederblad G 1988 Pharmacokinetics of intravenous and oral bolus doses of L-carnitine in healthy subjects. Eur J Clin Pharmacol 35:555-562

20. Millington DS, Maltby DA, Gale D, Roe CR 1989 Synthesis and human applications of stable isotope-labelled L-carnitine. In: Baillie TA, Jones JR (eds) Synthesis and Applications of Isotopically Labeled Compounds. Proceedings of the Third International Symposium, Innsbruck, Austria, July 1988. Elsevier Science Publishers B.V., Amsterdam, pp 189-194

21. Bohmer T, Behmer J 1958 Propionylcarnitine, physiological variations in vivo. Biochim Biophys Acta 152:559-567

22. Kodo N, Millington DS, Norwood DL, Roe CR 1989 Quantitative assay of free and total carnitine using tandem mass spectrometry. Clin Chim Acta 186:383-390

23. Millington DS, Norwood DL, Kodo N, Roe CR, Inoue F 1989 Application of fast atom bombardment with tandem mass spectrometry and liquid chromatography/mass spectrometry to the analysis of acylcarnitines in human urine, blood, and tissue. Anal Biochem 180:331-339

24. Brass EP, Hoppel CL 1978 Carnitine metabolism in the fasting rat. J Biol Chem 253:2688-2693

25. Millington DS, Terada N, Chace DH, Chen Yuan-T, Ding Jia-H, Kodo N, Roe CR 1992 The role of tandem mass spectrometry in the diagnosis of fatty acid oxidation disorders. In: Coates PM, Tanaka K (eds) New Developments in Fatty Acid Oxidation. Wiley-Liss, New York, pp 339-354

26. Heales SJR, Woolf DA, Robinson P, Leonard JV 1991 Rapid diagnosis of medium-chain acyl coA dehydrogenase deficiency by measurement of cis-4decenoic acid in plasma. J Inherit Metab Dis 14:661-667

27. Heales SJR, Leonard JV 1992 Diagnosis of medium chain acyl CoA dehydro- 
genase deficiency by measurement of cis-4-decenoic acid in dried blood spots. Clin Chim Acta 209:61-66

28. Millington DS, Kodo N, Terada N, Roe D, Chace DH 1991 The analysis of diagnostic markers of genetic disorders in human blood and urine using tandem mass spectrometry with liquid secondary ion mass spectrometry. Int J Mass Spectrom Ion Processes 111:211-228

29. Gross CJ, Henderson LM 1984 Absorption of D- and L-carnitine by the intestine and kidney tubule in the rat. Biochim Biophys Acta 772:209-219

30. Hamilton JW, Li BU, Shug AL, Olsen WA 1986 Carnitine transport in human intestinal biopsy specimens. Gastroenterology 91:10-16

31. Gudjonson H, Li BU, Shug AL, Olsen WA 1985 In vivo studies of intestinal carnitine absorption in rats. Gastroenterology 88:1880-1887

32. Li BUK, Lloyd ML, Gudjonsson H, Shug AL, Olsen WA 1992 The effect of enteral carnitine administration in humans. Am J Clin Nutr 55:838-845

33. Gross CJ, Henderson LM, Savaiano DA 1986 Uptake of L-carnitine, D carnitine and acetyl-L-carnitine by isolated guinea-pig enterocytes. Biochim Biophys Acta 886:425-433

34. Kelly JG, Hunt S, Doyle GD, Laher MS, Carmody M, Marzo A, Arigon Martelli E 1990 Pharmacokinetics of oral acetyl-L-carnitine in renal impairment. Eur J Clin Pharmacol 38:309-312

35. Parnetti L, Gaiti A, Mecocci P, Cadini D, Senin U 1992 Pharmacokinetics of IV and oral acetyl-L-carnitine in a multiple dose regimen in patients with senile dementia of Alzheimer type. Eur J Clin Pharmacol 42:89-93

36. McGarry JD, Foster DW 1980 Regulation of hepatic fatty acid oxidation and ketone body production. Annu Rev Biochem 49:395-420

37. McGarry JD, Woeltje KF, Kuwajima M, Foster DW 1989 Regulation of ketogenesis and the renaissance of carnitine palmitoyltransferase. Diabetes Metab Rev 5:271-284

38. Sweetman L 1989 Branched chain organic acidurias In: Scriver CR, Beaudet AL, Sly WS, Valle D (eds) The Metabolic Basis of Inherited Disease, 6th ed. McGraw-Hill, New York, pp 791-820

39. Rinaldo P, Schmidt-Sommerfeld E, Posca AP, Heales SJR, Woolf DA, Leonard JV 1993 Effect of treatment with glycine and L-carnitine in medium-chain acyl-coenzyme A dehydrogenase deficiency. J Pediatr 122:580-584

40. Millington DS, Roe CR, Maltby DA, Inoue F 1987 Endogenous catabolism is the major source of toxic metabolites in isovaleric acidemia. J Pediatr $110: 52-60$

41. Vazquez JA, Paul HS, Adibi SA 1988 Intravenously infused carnitine: influence on protein and branched-chain amino acid metabolism in starved and parenterally fed rats. Am J Clin Nutr 48:570-574

42. Tao RC, Peck GK, Yoshimura NN 1981 Effect of carnitine on liver fat and nitrogen balance in intravenously fed growing rats. J Nutr 111:171-177

43. Bowyer BH, Fleming CR, Ilstrup D, Nelson J, Burnes J 1986 Plasma carnitine levels in patients receiving home parenteral nutrition. Am J Clin Nutr 43:85-

44. Miotto G, Venerando R, Siliprandi N 1989 Inhibitory action of isovaleryl-Lcarnitine on proteolysis in perfused rat liver. Biochem Biophys Res Commun 158:797-802

45. Miotto G, Venerando R, Khurana KK, Siliprandi N, Mortimore GE 1992 Control of hepatic proteolysis by leucine and isovaleryl-L-carnitine through a common locus. J Biol Chem 267:22066-22072

46. Chalmers RA, de Sousa C, Tracey BM, Stacey TE 1985 L-Carnitine and glycine therapy in isovaleric acidaemia. J Inherit Metab Dis 8[Suppl 2]:141-142

47. Mayatepek E, Kurckzynski TW, Hoppel CL 1991 Long-term L-carnitine treatment in isovaleric acidemia. Pediatr Neurol 7:137-140 